\section{Perioperative interruption of dual antiplatelet therapy}

NOVEMBER 2017

TO THE EDITOR: We read with great interest the article by Munyon et $\mathrm{al}^{1}$ addressing recent developments in perioperative medicine. We would like to comment on the perioperative interruption of dual antiplatelet therapy, a common clinical problem.

Several registry analyses have shown that, with second-generation drug-eluting stents, interruption of 1 antiplatelet agent after the first month is safe. ${ }^{2,3}$ These registries included a substantial proportion of patients whose index stenting procedure was performed for acute coronary syndrome (up to $60 \%$ ). ${ }^{2} \mathrm{On}$ average, antiplatelet therapy interruption was brief (about 6 to 7 days).

Additional registry analyses have shown that surgery may be safely performed beyond the first month after drug-eluting stent placement. ${ }^{4,5}$ Specifically, a large Danish analysis of patients with a drug-eluting stent who underwent noncardiac surgery, matched to control patients without ischemic heart disease, showed that the risk of perioperative myocardial infarction and death was not increased beyond the first month after drug-eluting stent implantation. Specifically, the risk was not increased at the 1- to 2-month and 2- to 12 -month postimplantation intervals. Acute coronary syndrome was the indication for stenting in $56 \%$ of the patients.

Therefore, while surgery is preferably delayed 6 months after drug-eluting stent implantation (class I recommendation in the European Society of Cardiology guidelines), surgery may be selectively performed 1 to 6 months after drug-eluting stent implantation with an acceptable risk. This is particularly so if the index stenting was performed in the setting of stable coronary arterial disease (class Ila recommendation if stenting was performed in the setting of stable coronary arterial disease without complex procedural features; class IIb recommendation if stenting was performed in the setting of acute coronary syndrome or complex procedural fea- tures) ${ }^{6}$ After drug-eluting stent implantation, the earliest cutpoint for considering surgery is 1 month rather than 3 months.

When surgery is performed within this 1 - to 6-month interval, thienopyridine interruption should be kept brief and dual antiplatelet therapy reinitiated as soon as possible postoperatively. In fact, when thienopyridine therapy is interrupted 1 to 6 months after drug-eluting stent implantation, stent thrombosis typically occurs more than 6 or 7 days after interruption. ${ }^{?}$

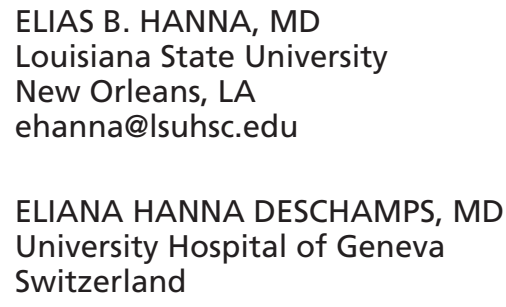

1. Munyon R, Cohn SL, Slawski B, Smetana GW, Pfeifer K. 2017 update in perioperative medicine: 6 questions answered. Cleve Clin J Med 2017; 84(11):863-872. doi: 10.3949/ccjm.84a.17068.

2. Ferreira-Gonzáles, Marsal JR, Ribera A, et al. Dual antiplatelet therapy after drug-eluting stent implantation: risk associated with discontinuation within the first year. J Am Coll Cardiol 2012; 60(15):1333-1339. doi: 10.1016/j. jacc.2012.04.057.

3. Naidu SS, Krucoff MW, Rutledge DR, et al. Contemporary incidence and predictors of stent thrombosis and other major adverse cardiac events in the year after XIENCE $\checkmark$ implantation: results from the 8,061-patient XIENCE V United States study. JACC Cardiovasc Interv 2012; 5(5):626-635. doi: 10.1016/j.jcin.2012.02.014.

4. Egholm G, Kristensen SD, Thim T, et al. Risk associated with surgery within 12 months after coronary drugeluting stent implantation. J Am Coll Cardiol 2016; 68(24):2622-2632. doi: 10.1016/j.jacc.2016.09.967.

5. Singla S, Sachdeva R, Uretsky BF. The risk of adverse cardiac and bleeding events following noncardiac surgery relative to antiplatelet therapy in patients with prior percutaneous coronary intervention. J Am Coll Cardiol 2012; 60(20):2005-2016. doi: 10.1016/j.jacc.2012.04.062.

6. Valgimigli M, Bueno H, Byrne RA, et al. 2017 ESC focused update on dual antiplatelet therapy in coronary artery disease developed in collaboration with EACTS: The Task Force for dual antiplatelet therapy in coronary artery disease of the European Society of Cardiology (ESC) and of the European Association for Cardio-Thoracic Surgery (EACTS). Eur Heart J 2018; 39(3):213-260. doi: 10.1093/ eurheartj/ehx419.

7. Airoldi F, Colombo A, Morici N, et al. Incidence and predictors of drug-eluting stent thrombosis during and after discontinuation of thienopyridine treatment. Circulation 2007; 116(7):745-754. doi: 10.1161/CIRCULATIONAHA.106.686048

doi:10.3949/ccjm.85c.04001 
IN REPLY: We reported on publications from 2016-2017 and, unfortunately, at the time we were writing our paper, the European Society of Cardiology (ESC) update on dual antiplatelet therapy ${ }^{1}$ had not yet been published. We presented the recommendations from the American College of Cardiology (ACC) and American Heart Association (AHA), ${ }^{2}$ which differ from the recently published ESC guidelines. The ESC suggests that the minimum waiting period after drug-eluting stent placement before noncardiac surgery should be 1 month rather than 3 months but acknowledges that in the setting of complex stenting or recent acute coronary syndrome, 6 months is preferred. The recommendation in this latter scenario is a class IIb $\mathrm{C}$ recommendation-essentially expert consensus opinion.

Further, in the study by Egholm et $\mathrm{al}^{3}{ }^{3}$ the event rates in patients undergoing noncardiac surgery in the 1 - to 2 -month period were numerically higher than in the control group, and no adjusted odds ratios were given.

The numbers of events were very low, and a change of only 1 or 2 events in the other direction in the groups would likely make it statistically significant.

All of these recommendations are based on observational studies and registry data, as there are no randomized controlled trials to address this issue. There are many complexities to be accounted for including the type of stent, timing, circumstances surrounding stenting, anatomy, number of stents, patient comorbidities (particularly age, diabetes mellitus, cardiac disease), type of surgery and anesthesia, and perioperative management of antiplatelet therapy. While we acknowledge the ESC recommendation, we would urge caution in the recommendation to wait only 1 month, and in the United States most would prefer to wait 3 months if possible.

RYAN MUNYON
Penn State University
Hershey, PA
rmunyon@pennstatehealth.psu.edu

STEVEN L. COHN, MD, FACP, SFHM University of Miami Miller School of Medicine Miami, FL

BARBARA SLAWSKI, MD, MS, SFHM Medical College of Wisconsin Milwaukee

GERALD W. SMETANA, MD, MACP Harvard Medical School Boston, MA

KURT PFEIFER, MD, FACP, SFHM Medical College of Wisconsin Milwaukee

-REFERENCES

1. Valgimigli M, Bueno H, Byrne RA, et al. 2017 ESC focused update on dual antiplatelet therapy in coronary artery disease developed in collaboration with EACTS: The Task Force for dual antiplatelet therapy in coronary artery disease of the European Society of Cardiology (ESC) and of the European Association for Cardio-Thoracic Surgery (EACTS). Eur Heart J 2018; 39(3):213-260. doi: 10.1093/ eurheartj/ehx419.

2. Levine GN, Bates ER, Bittl JA, et al. 2016 ACC/AHA guideline focused update on duration of dual antiplatelet therapy in patients with coronary artery disease. Circulation 2016; 134(10):e123-e155. doi: 10.1161/ CIR.0000000000000404.

3. Egholm G, Kristensen SD, Thim T, et al. Risk associated with surgery within 12 months after coronary drugeluting stent implantation. J Am Coll Cardiol 2016; 68(24):2622-2632. doi: 10.1016/j.jacc.2016.09.967.

doi:10.3949/ccjm.85c.04002 